
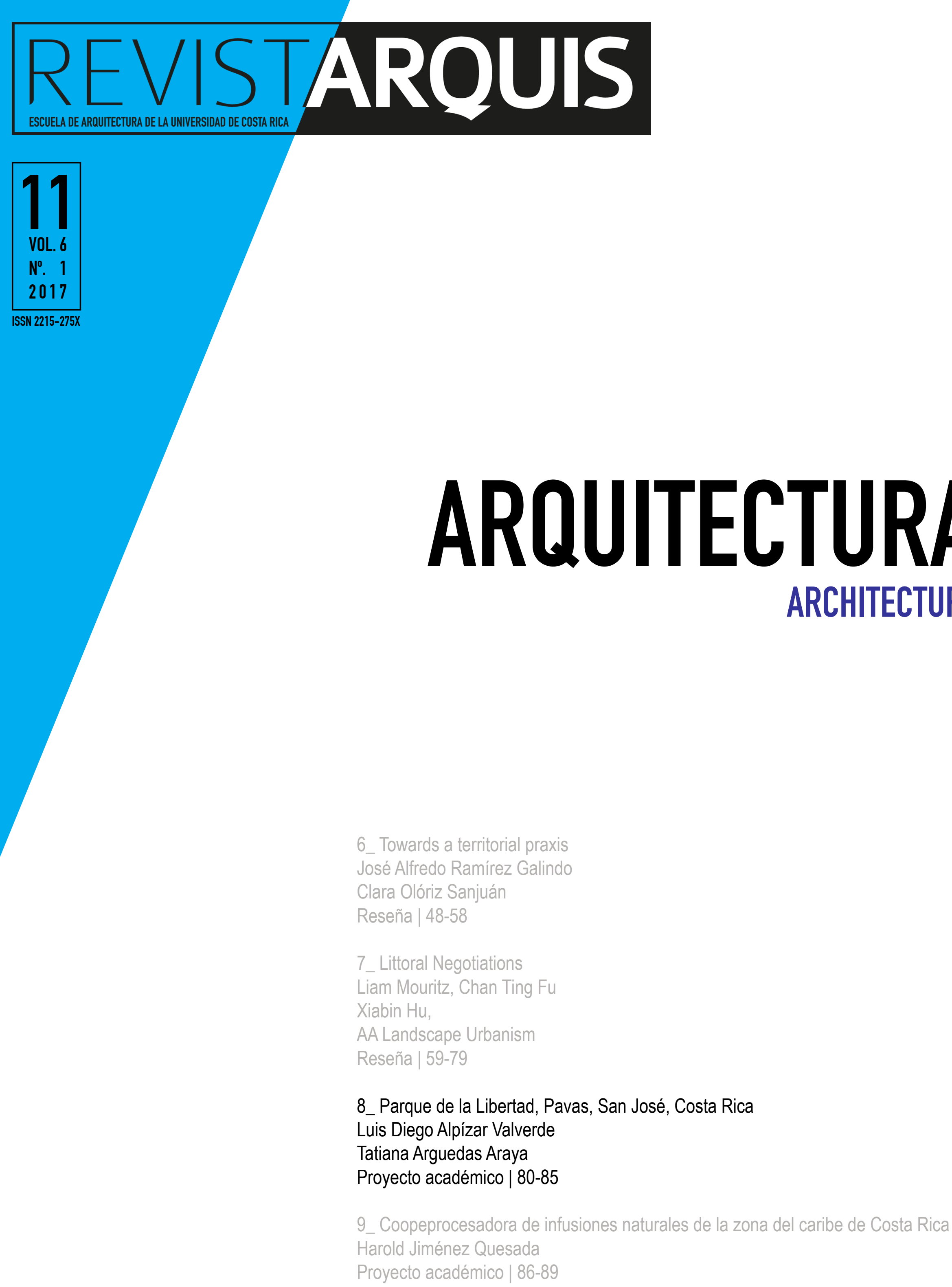

8_Parque de la Libertad, Pavas, San José, Costa Rica Luis Diego Alpízar Valverde

Tatiana Arguedas Araya

Proyecto académico | 80-85

9 Coopeprocesadora de infusiones naturales de la zona del caribe de Costa Rica Harold Jiménez Quesada

Proyecto académico | 86-89 


\section{Parque de la Libertad, Pavas, San José, Costa Rica}

Proyecto académico

Recibido: 30 de marzo del 2017

Aceptado: 19 de mayo 2017

\section{Nombre del Proyecto}

Parque Recreativo La Libertad, Pavas.

\section{Arquitectos}

Luis Diego Alpízar Valverde

Tatiana Arguedas Araya

\section{Propietario y Colaboradores}

Municipalidad de San José

Financiamiento Futura Ejecución (Premio Bono Comunal MIVAH). Grupo Mutual Alajuela La Vivienda de Ahorro y Préstamo

\section{Ubicación del proyecto}

Provincia: San José. Cantón: San José. Distrito: Pavas. Barrio: La Libertad y la Esperanza.

\section{Presupuesto}

$427,500,000.00$ colones

\section{Año realización Anteproyecto \\ 2013}

\section{Superficie de Terreno}

$14569 \mathrm{~m} 2$

\section{Visualizaciones, fotografías e imágenes Luis Diego Alpízar Valverde}

Tatiana Arguedas Araya

\section{Luis Diego Alpízar Valverde}

Licenciado en Arquitectura. Universidad Véritas, Costa Rica. Cursando la maestría de gerencia de proyectos. Universidad Latina de Costa Rica. Fundador de Avant arquitectura y diseño, firma especialista en proyectos multidisciplinarios de arquitectura, urbanismo, diseño gráfico y animación 3D. Encargado del diseño, administración y ejecución de proyectos en la empresa constructora Alianz Estudio.

\section{Tatiana Arguedas Araya}

Licenciada en Arquitectura. Universidad Véritas, Costa Rica. Máster en Tecnología, Gestión y Rehabilitación de la Edificación. Universidad de Cantabria, España. Especializada en Temas de Participación, Sensibilización y Comunicación Ciudadana. Encargada del diseño, administración y ejecución de proyectos en la empresa constructora ARCOM S.A., negocio familiar de más de 30 años en el mercado costarricense. Coordinadora del área de Participación, Sensibilización y Comunicación Ciudadana del Centro Para la Sostenibilidad Urbana. Asesora en Participación, Sensibilización y Comunicación Ciudadana aplicados a temas de Movilidad Urbana, en la Federación Metropolitana de Municipalidades de San José.

\author{
Luis Diego Alpizar Valverde \\ Tatiana Arguedas Araya
}

\section{Resumen}

El parque Recreativo La Libertad de Pavas nace como un proyecto comunal universitario realizado para la Municipalidad de San José en el año 2013, ganador posteriormente del Primer Concurso "Espacios innovadores para la recreación y la convivencia comunitaria" del Ministerio de Vivienda y Asentamientos Humanos (MIVAH), en el año 2015. Actualmente, el proyecto se encuentra en la etapa de elaboración de planos constructivos y tramitología de permisos de construcción, con la expectativa de empezar la etapa constructiva en el 2018.

La propuesta busca el rescate de una comunidad con importantes problemáticas sociales, como lo es La Libertad de Pavas, mediante el otorgamiento de un espacio del cuál se puedan apropiar. Lugar donde puedan practicar deporte y donde se fomente la recreación sana de sus habitantes. Como resultado, la propuesta cuenta con un programa de nuevas actividades como el bicicross, skateboarding, fútbol, zonas de descanso, áreas de recreación, espacios feriales y una serie de senderos, que dan una nueva dinámica al sitio. También, se realizó un estudio específico de vegetación para la zona, ya que esta juega un papel importante dentro de la conceptualización arquitectónica, así como el juego con la topografía que se quiere lograr. Este nuevo programa y actividades de la propuesta, invita a los habitantes de Pavas a apropiarse de este espacio y cuidarlo como suyo, mediante actividades para diferentes edades a lo largo del trayecto y darle una nueva imagen a su comunidad.

Palabras clave: deporte; recreación; apropiación espacial; comunidad.

\section{Abstract}

The recreational park La Libertad, Pavas was born as a communal project carried out for the Municipality of San José in 2013, winner of the First Contest "Innovative space for recreation and community coexistence" of MIVAH year 2015. It is currently in the stage of elaboration of constructive plans and permissions.

The proposal seeks to rescue a community with social problems, such as La Libertad de Pavas, through the granting of a space where they can practice sports and encourage the recreation of its inhabitants. As a result, the project has a study of vegetation specific to this area, as well as its topography, where new activities such as bicicross, Skateboarding, football, recreation areas, fairgrounds and a series of trails were adapted; which give a new dynamic to the site. The new program of the proposal invites the community of Pavas to appropriate the park, presenting activities for different ages along the way.

Keywords: sport; recreation; space appropriation; community. 


\section{Componente Sociodemográfico}

egún datos del censo del 2011, Pavas cuenta con una población de 71.384 habitantes, de los cuales, 33.878 son hombres y 37.506 son mujeres. Pavas distrito, según este mismo censo, cuenta con una densidad poblacional de 7.643 habitantes por kilómetro cuadrado, cifra bastante alta.

Otra particularidad, y principal problemática de este distrito, es que alberga 15 de los 37 precarios en el Cantón de San José 1 . Un 40\% de los precarios de San José se encuentran en Pavas y muchos de ellos están ubicados en áreas destinadas a parques según el Uso de Suelo establecido por el Municipio. Esto se debe a que una de las necesidades más fuertes de los pobladores del distrito, es la carencia de vivienda, lo que hace a estos terrenos destinados a ser parques, vulnerables a las invasiones.

Específicamente, los barrios de La Libertad y Villa Esperanza; donde se emplaza la propuesta, cuentan con una población total de 12.053 personas, siendo este el número de personas beneficiadas con esta intervención planeada para el Parque La Libertad y su impacto positivo en la comunidad.

\section{Contexto Histórico Parque La Libertad}

El terreno donde se emplaza la propuesta en el pasado estuvo ocupado por más de 300 viviendas informales, que albergaban a un número aproximado de 1000 familias, donde el promedio de ocupación variaba entre dos y cuatro familias por vivienda. La mayoría de la población de este terreno eran inmigrantes nicaragüenses, por este motivo este lugar se conocía comúnmente, hace unos años como "La Managüita" de Pavas.
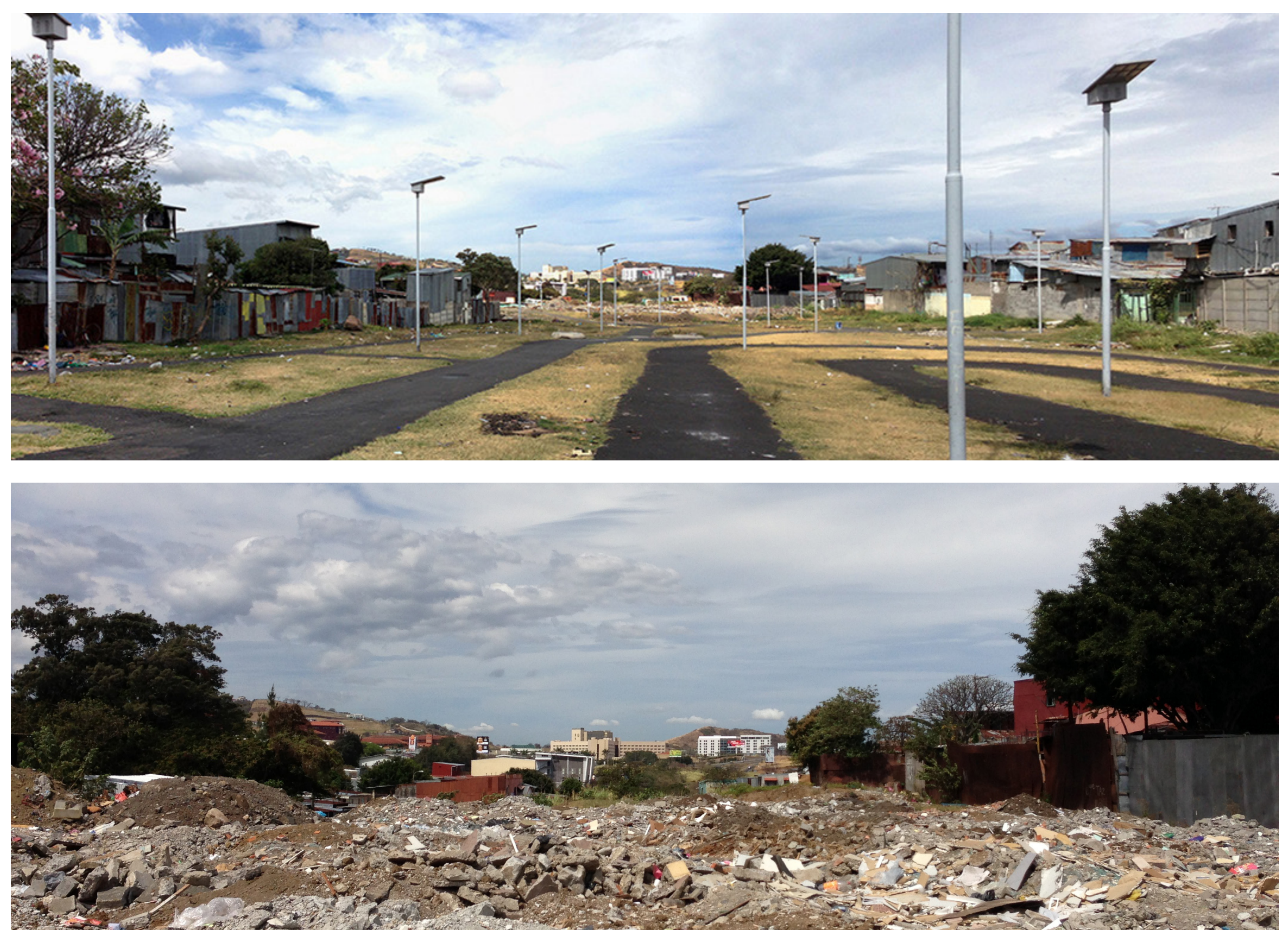
En el año 2006 la Sala Constitucional ordenó su desalojo, siendo justificada esta decisión por la no correspondencia del uso del suelo del terreno y la amenazante situación de que las aguas residuales de la comunidad pasaban por este; situación comprometedora para la salud de estos pobladores que se mantiene actualmente. En febrero del 2006, se notificó formalmente a los habitantes de las 300 viviendas el desalojo; sin embargo, unos meses después se tuvo que aplicar desalojo forzoso a las familias que no querían abandonar el terreno para poder eliminar al 100\% las viviendas informales de este.

Tiempo después del desalojo total, la Municipalidad de San José, inició el proceso de rehabilitación del parque, construyendo senderos, redes para aguas pluviales y colocando luminaria urbana de tipo solar. Pero, por razones no conocidas, el terreno sufrió abandono por parte de la Municipalidad. Algunos vecinos se aprovecharon de la situación para depositar allí sus residuos sólidos, convirtiéndolo en un botadero a cielo abierto, condición que no ha cambiado hasta el día de hoy.

\section{Programa Parque La Libertad}

El Parque Recreativo La Libertad, con una extensión de $14569 \mathrm{~m}^{2}$ aproximadamente, contará con el siguiente programa y zonificación, realizado a partir de las necesidades de la comunidad.

Áreas de juegos infantiles y ejercicio para adultos.

1 Cancha Multiuso.

$1240 \mathrm{~m}^{2}$ de senderos construidos.

$7120 \mathrm{~m}^{2}$ de áreas verdes.

1 Pista de SkatePark.

1 Pista de Bicicross.

1 zona ecológica que contempla la plantación de 382 árboles, de especies nativas.

Mobiliario, luminarias urbanas y casetilla para seguridad y mantenimiento del Parque.

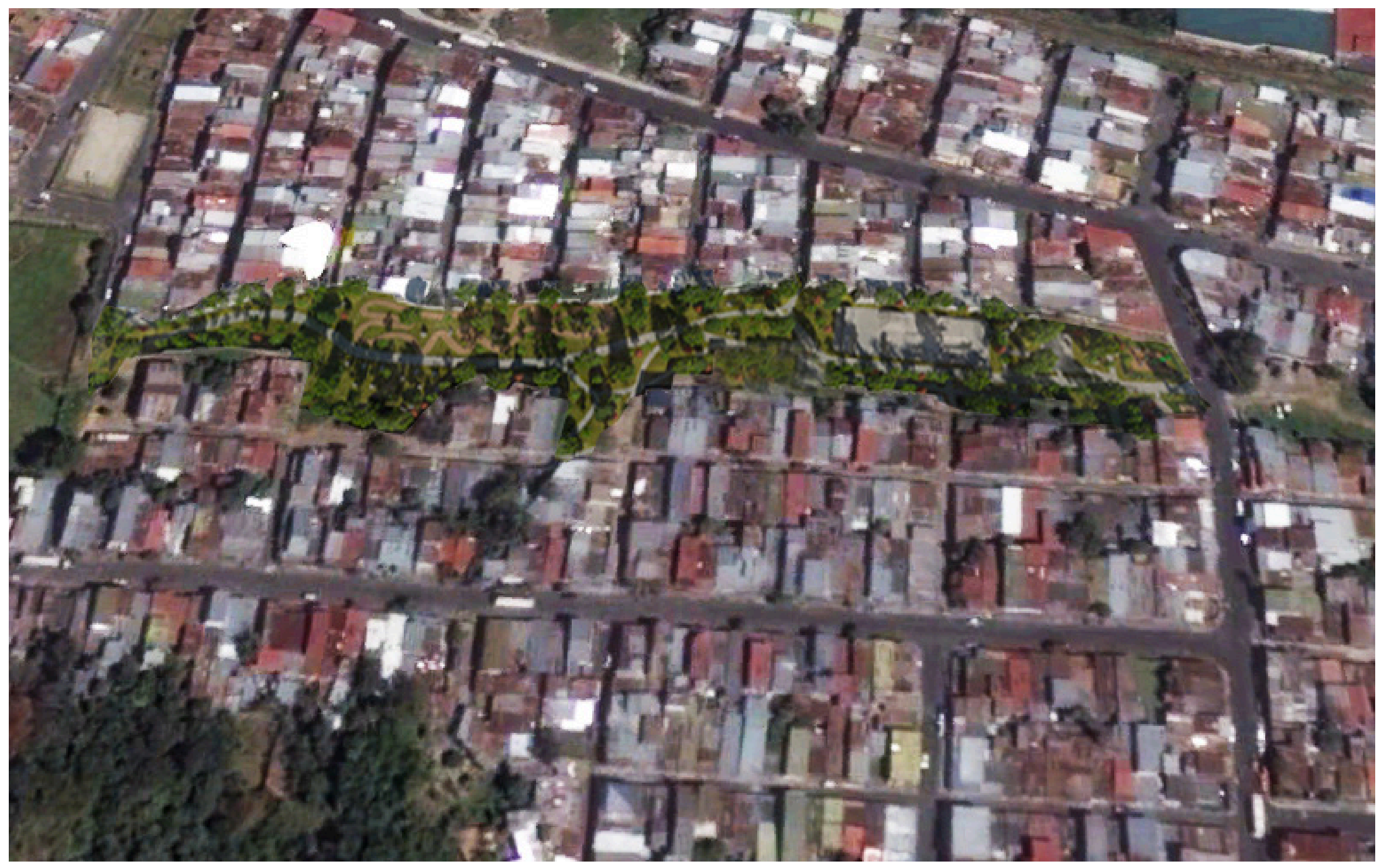




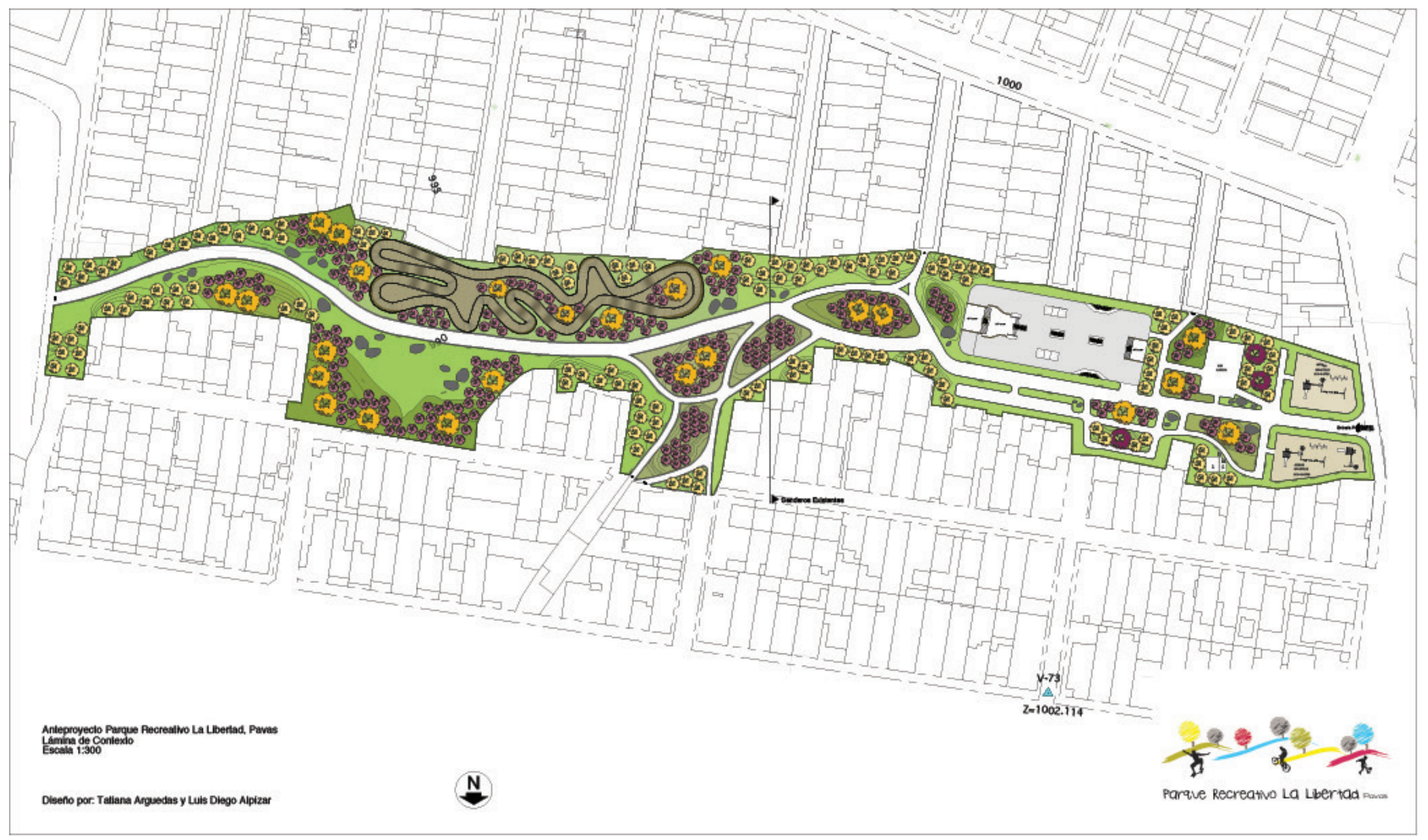

Figura 3. Plano de anteproyecto. A

Parque Recreativo La Libertad, Pavas.
Figura 4. Conjunto anteproyecto.

Parque Recreativo La Libertad, Pavas. Y

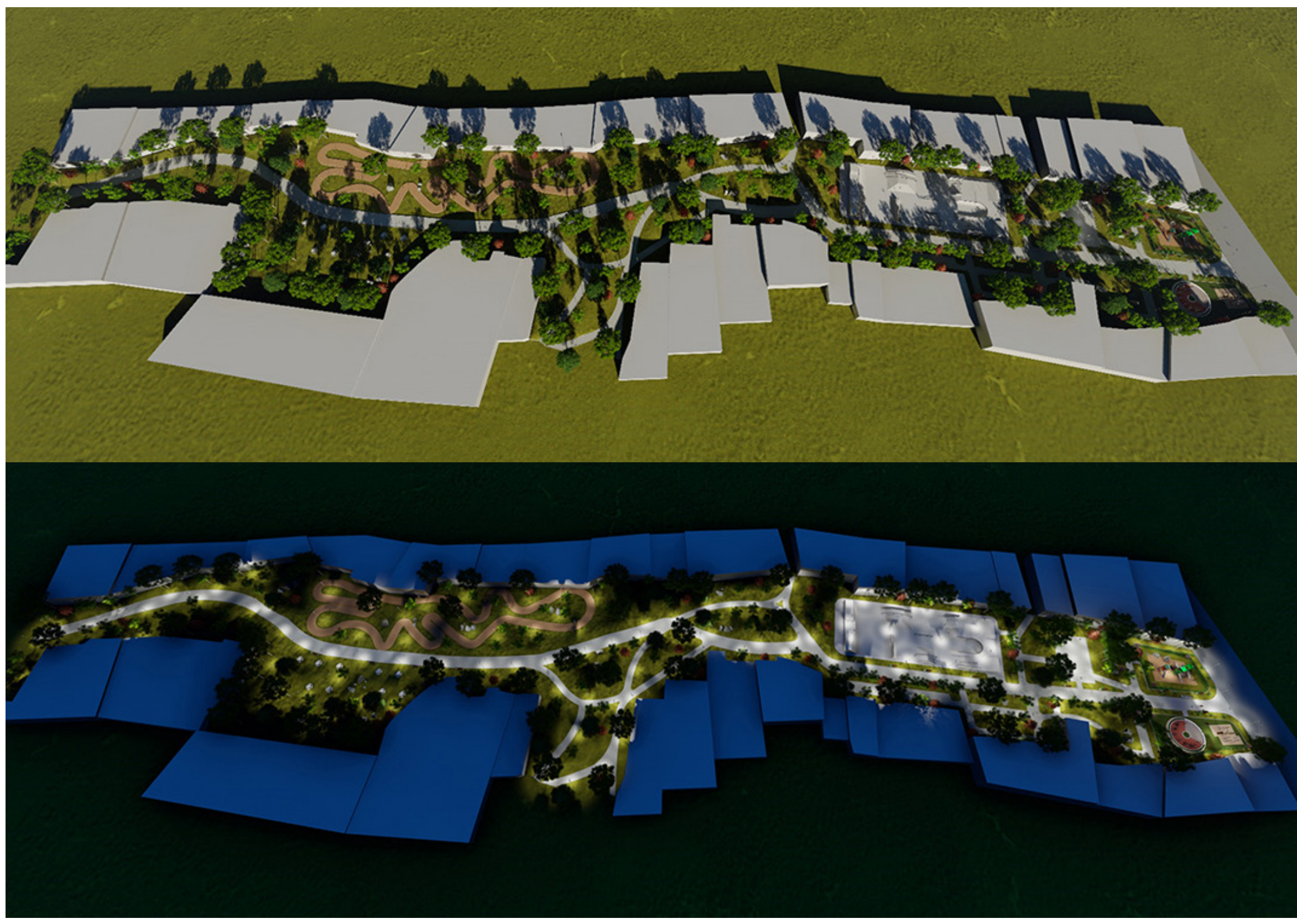


Figura 4. Vistas de anteproyecto.

Parque Recreativo La Libertad, Pavas.
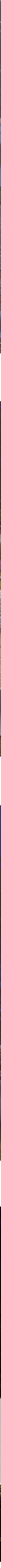
Figura 4. Vista nocturna de anteproyecto. Parque Recreativo La Libertad, Pavas.

Parque de la Libertad, Pavas, San José, Costa Rica

Ganador del Primer Concurso de Bono Comunal MIVAH (Ministerio de Vivienda y Asentamientos Humanos, Costa Rica) "Áreas verdes recreativas. Espacios innovadores para la recreación y la convivencia comunitaria".

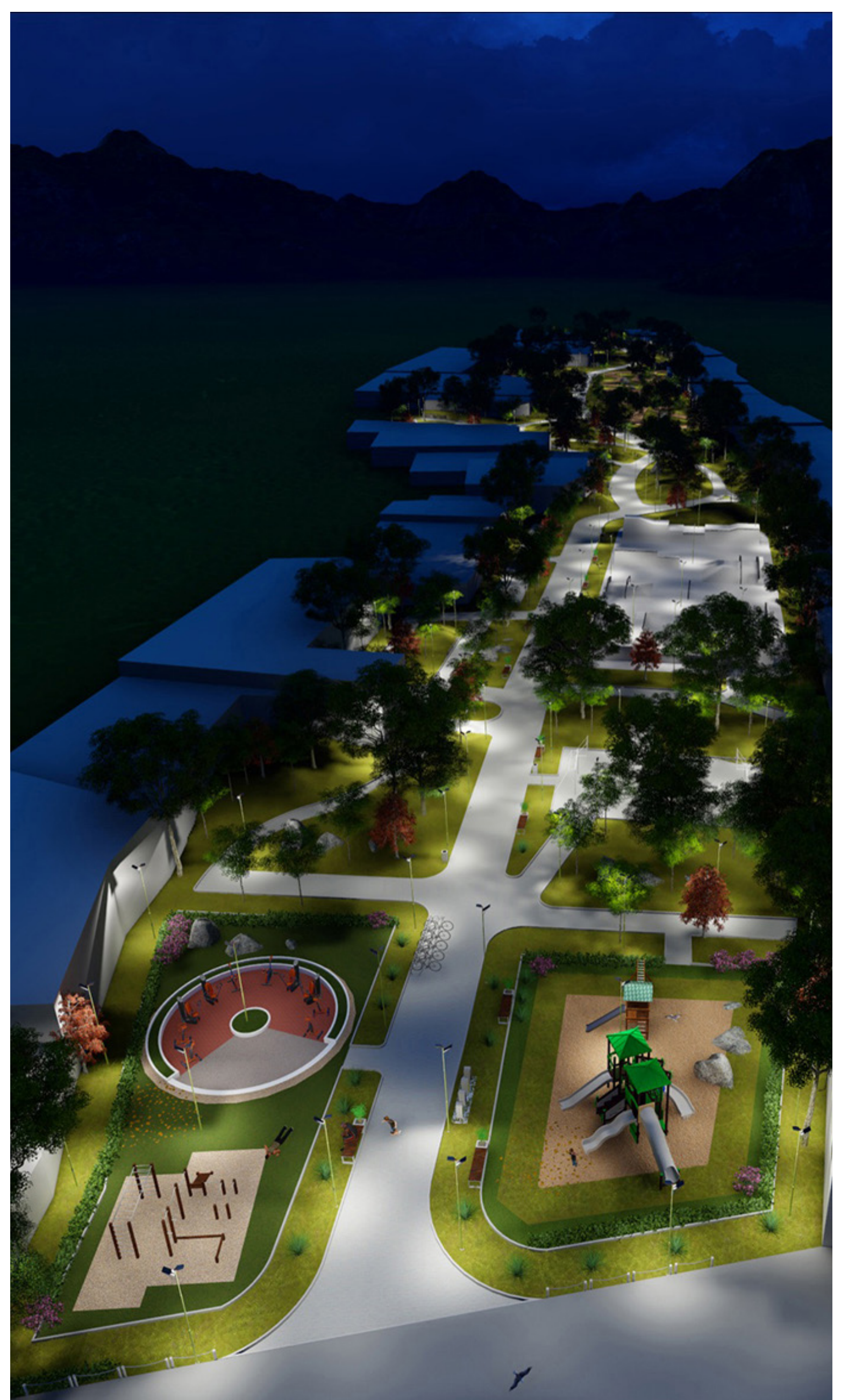

\section{Conclusión}

Este proyecto una vez construido, busca ofrecer condiciones óptimas para la práctica y aprovechamiento del tiempo libre a nivel recreativo tanto para los niños y jóvenes, como para la comunidad en general, como medio para el mejoramiento de la calidad de vida. Haciendo de las actividades recreativas un medio socializador que permita la integración y participación familiar y comunitaria que contribuya a reducir problemáticas sociales tan comunes de este distrito, como lo son la delincuencia, el alcoholismo y la drogadicción.

Como efecto secundario positivo de esta intervención, se espera lograr la integración de la comunidad y reforzar el sentido de pertenencia por su entorno, esperando que este se contagie entre los pobladores de este distrito. 